\title{
La memoria del horror: la representación escénica de los campos de concentración
}

\author{
Alba Saura Clares \\ Universidad de Murcia \\ Departamento de Literatura Española, Teoría de la Literatura y Literatura Comparada \\ alba.saura@um.es
}

\begin{abstract}
RESUMEN
A través de este estudio nos acercaremos a las representaciones teatrales cuya temática ahonda en la experiencia vivida en los campos de concentración durante el Holocausto. Entre las obras dedicadas a este tema, centraremos nuestro corpus en dos propuestas: El campo (1968) de la escritora argentina Griselda Gambaro y J'attendrai (2014) del español José Ramón Fernández. Esta elección nos permitirá analizar las particularidades y diferentes formulaciones sobre este tema: la distancia temporal de ambos textos con el hecho histórico; las características de cada contexto de producción (la Argentina dictatorial, la España democrática); el deseo de crítica contra la opresión frente a la reivindicación memorialística; el estilo neovanguardista de Gambaro frente a un realismo poético de Fernández... En definitiva, estos textos nos permitirán observar disímiles formas de recreación estética y temática del horror vivido en los campos de concentración.
\end{abstract}

Palabras clave: teatro, campos de concentración, Griselda Gambaro, José Ramón Fernández, Argentina, España.

\section{The memory of the horror: performing the concentration camps}

\begin{abstract}
This paper focuses on the dramatic works about the experience on the concentration camps during the Holocaust. Among the plays addressing this theme, this study concentrates on two works: El campo (1968), by the Argentinian playwright Griselda Gambaro and J'attendrai (2014), by the Spanish playwright José Ramón Fernández. This corpus will be useful to analyse the characteristics and different perspectives on this common subject: the temporal distance between each of the plays and the historical events; their different context of production (the dictatorship in Argentina; the democracy in Spain); the desire to criticize the oppression in contrast to the claim on historical memory; Gambaro's Neovanguardia style and Fernández's poetic realism... In short, the corpus examined will enable the examination of dissimilar ways to reproduce, both aesthetically and thematically, the horror lived in concentration camps.
\end{abstract}

Keywords: theater, concentration camps, Griselda Gambaro, José Ramón Fernández, Argentinian, Spain. 
«Sólo una cosa no hay. Es el olvido» («Everness», Jorge Luis Borges)

«Yo.- Además, la historia se la come el polvo. A la literatura, a veces, no. Si la obra que escribo vale la pena como literatura, como arte, será leída dentro de veinte años, cuando yo ya esté muerto, cuando los hijos de esos españoles en Mauthausen sean ancianos o hayan dejado de existir».

(J'attendrai. José Ramón Fernández)

\section{Reconstruyendo el horror}

El siglo XX se vio marcado por el horror: dos guerras mundiales, diferentes enfrentamientos bélicos nacionales, violencia social, genocidios, revoluciones, opresión, dictaduras, autoritarismo, terror... Tras esta oleada de espanto, llegó la calma y el deseo de reconstrucción material y social. Se generó la necesidad de borrar la huella traumática que desolaba a los diferentes países según sus historias nacionales y compartidas, conjugando, con los diferentes procesos transicionales y la llegada de las democracias, la difícil tensión entre el perdón y la justicia, el olvido y la memoria. Brotó, entonces, finalizando el siglo XX y afianzándose en el XXI, un nuevo pensamiento crítico que reflexiona sobre estos acontecimientos y sus consecuencias socioculturales en los discursos memorialísticos, construyéndose el papel de la memoria en los diferentes países y debatiendo su funcionalidad, formulaciones y características. Este efecto es lo que Beatriz Sarlo denominaría como el «giro subjetivo» (2005):

Este reordenamiento ideológico y conceptual de la sociedad del pasado y sus personajes, que se concentra sobre los derechos y la verdad de la subjetividad, sostiene gran parte de la empresa reconstructiva de las décadas del sesenta y setenta. Se ha restaurado la razón del sujeto [...] la historia oral y el testimonio han devuelto la confianza a esa primera persona que narra su vida (privada, pública, afectiva, política), para conservar el recuerdo o para reparar una identidad lastimada. (Sarlo 2005: 22)

Como también apuntan los trabajos de Elizabeth Jelin en este campo, se constata actualmente:

La creciente atención prestada, en la esfera pública y en el campo académico, a las memorias del pasado reciente [...] Se trata de expresiones producidas por actores y movimientos sociales diversos y por políticas estatales que responden a las demandas de estos actores sociales. (Jelin 2014: 226)

En base a este contexto, este estudio se acerca a un arte concreto, el teatro, y a las representaciones escénicas del horror vivido en los campos de concentración 
nazi ${ }^{1}$. La elección del teatro se encuentra motivada por su carácter «convivial» (Dubatti 2007), característica que lo diferencia de otras expresiones artísticas y que genera una recepción distinta en temáticas como las que aquí nos enfrentamos. El convivio se alcanza en cada escenificación, generándose un acto compartido en comunidad, el cual provoca una relación directa entre el emisor de la representación y el espectador que la recibe. De esta forma, en el teatro, como arte realizado en vivo, y motivado por su carácter dialogal, resulta tan determinante el agente emisor como el público asistente:

Sucede que el espectáculo es también el espectador. Los espectadores como espectáculo. En el convivio uno percibe en los espectadores el espectáculo de la emoción o el aburrimiento, de la simpatía o el rechazo, [...] del pensamiento, del sentimiento, de la memoria. [...] del triunfo o el fracaso del actor, que logra que los espectadores se dejen conducir por él, o que no lo logra. El espectáculo de uno mismo: vivir y verse vivir en el convivio. (Dubatti 2007: 59)

Por ello, se construye una vivencia colectiva, una experiencia disímil a las otras artes que fomenta el encuentro, la reflexión grupal y social y, en el caso de temáticas como la que aquí nos concierne, la retentiva en comunidad sobre la experiencia traumática de los campos de concentración.

Para este trabajo, hemos delimitado un corpus formado por dos textos del ámbito hispánico, con el fin de mostrar la evolución en la representación escénica de la temática de los campos de concentración según la distancia histórica: el cambio hacia los discursos memorialísticos, las diferentes estrategias escénicas, los tópicos y formulaciones temáticas, así como la propia intencionalidad de cada autor. Nos referimos a El campo (1968) de la argentina Griselda Gambaro y a J'attendrai (2014) del español José Ramón Fernández.

\section{Violencia, crueldad y metáfora: El campo de G. Gambaro}

Entre el periodo que abarca desde la caída del gobierno autoritario de Hipólito Yrigoyen (1930) y la última dictadura militar, el autodenominado Proceso de Reorganización Nacional (1976-1983), Argentina se vio marcada por una gran inestabilidad sociopolítica ${ }^{2}$. Es en este complejo contexto sociopolítico donde se desarrolla la carrera dramática de Griselda Gambaro ${ }^{3}$, una de las voces más destacadas de la dramaturgia y la cultura argentina del siglo Xx. Se trata de una producción comprometida, en lo temático y estético: un teatro reivindicativo y de carácter político, expresado desde la Neovanguardia, estilo que ella misma inaugura con el estreno de

\footnotetext{
1 Para una profundización en la llamada «literatura de los campos», las expresiones que abarca y sus características, remitimos al trabajo de Sánchez Zapatero (2010).

2 Para una profundización en este período, remitimos al trabajo de José Manuel Azcona (2010).

3 Un completo estudio sobre la obra de esta autora es el realizado por Susana Tarantuviez (2007).
} 
El desatino en 1964. Como señala Susana Tarantuviez, existen una serie de ejes temáticos que circundan toda la obra gambariana a lo largo de su producción: el abuso de poder, la opresión, la violencia, la tortura, la relación entre la víctima y el victimario, la pasividad de las víctimas... temas de la primera etapa que, a partir de los ochenta, darán paso a la representación de lo femenino, la construcción de la memoria, la cuestión del otro o la realidad del deseo, entre otros (Tarantuviez 2007: 112-115).

El campo es uno de los títulos más destacados de su trayectoria, perteneciente a su primera etapa ${ }^{4}$. En esta obra, Gambaro reflexiona sobre los campos de concentración nazi, a veinte años del descubrimiento del horror, con el fin de correlacionarlo con la realidad argentina de su tiempo. En la obra, Martín llega a un lugar desconocido donde cree que trabajará como contable. Allí le recibirá Franco, director del centro, vestido con un uniforme de las SS, y Emma. Entre la marcada violencia de la propuesta y el absurdo de los diálogos y situaciones, el espectador se enfrentará a un espacio de extrañeza, de mensajes contradictorios que se descodifican con el avance del texto: descubriremos la represión tras la amabilidad de Franco, la tortura física y psicológica ejercida hacia Emma -víctima y cómplice del opresor al que es incapaz de enfrentarse-, y constataremos que Martín ha sido encerrado en un campo de concentración.

El campo muestra la cercanía de Gambaro al Teatro del Absurdo, pero también a la estética del Teatro de la Crueldad. Los juegos verbales y diálogos inverosímiles generan la comicidad, el sinsentido nos conduce al humor negro y se antepone lo trágico del argumento y de las acciones violentas a la respuesta pasiva de las víctimas y la normalización de la crueldad por parte de los opresores. Por ello, la obra finaliza con la marca a fuego como preso de Martín, incapaz de rebelarse, frente al tono amigable de los agresores:

Enfermero.- (con naturalidad) También camiseta... Está muy abrigado usted...

(Le sonríe amigablemente. La sonrisa es común, completamente distanciada de lo que está sucediendo. [...] Los otros dos lo sostienen con una especie de bondad, uno de ellos saca un pañuelo del bolsillo y le seca el sudor de la cara). (Gambaro 1990: 214)

Se trata de una elección estética, por parte de Gambaro, sorprendente en esta temática. Su motivación responde al deseo de la dramaturga por acercarse al hecho histórico -en el momento de su escritura cercano para el público- buscando la reflexión crítica y la correlación con el contexto represivo argentino. De ahí la ironía establecida desde el propio título y extendida en todo el texto: lejos de un campo idílico, nos encontramos ante la realidad concentracionaria. En este sentido, consideramos que algunas de las claves para comprender este acercamiento de Gambaro a

${ }^{4}$ Seguimos la periodización de la obra de Gambaro realizada por Osvaldo Pellettieri. Según este crítico, la primera etapa correspondería al «absurdo gambariano» (1965-1968), «una variante del absurdo de amenaza. Trabaja en complementariedad con sus reglas obligatorias y las fusiona con el modelo irracionalista preexistente, el expresionismo» (Pellettieri 2003: 316). A esta etapa pertenece $E l$ desatino (1965), Las paredes y Matrimonio (1966), Los siameses (1967) y El campo (1968). 
la temática concentracionaria se encuentran en el juego establecido con el referente nazi, la focalización en Martín, la víctima, y el tratamiento de la violencia, como analizaremos.

La recepción de la propuesta de Gambaro en su estreno en 1968 fue polémica, ya que se estableció una única correspondencia con la realidad vivida durante la represión nazi, lo que condujo a una crítica hacia la autora, considerando que eludía la realidad opresiva de su país. Empero, como señala Méndez-Faith: «El nazismo sirve aquí de metáfora, que alude a todo sistema totalitario -incluso el argentino, por supuesto- y a sus métodos de crueldad y tortura» (Méndez-Faith 1985: 837). Una lectura profunda del texto nos permite ver los rasgos con los que juega Gambaro para la metaforización, desde las expresiones porteñas de Franco, la sorpresa y extrañamiento de Martín ante el uniforme de las SS o las referencias al conflicto bélico en Vietnam, hecho posterior al régimen nazi. Se establece, por tanto, «un modo metafórico de textualización ya que el texto no es transparente en cuanto a la mostración del referente, sino que instaura una comparación tácita entre lo representado en escena y la realidad a la que se alude» (Tarantuviez 2007: 193).

El campo no se inscribe, por lo que observamos, en las representaciones memorialísticas. Por el contrario, se trata de un teatro de carácter político, reivindicativo y comprometido ${ }^{5}$. De ahí que la propuesta focalice al espectador en la figura de Martín, de la víctima. Nos aturdimos junto al personaje y con él descubrimos las señales que nos indican lo extraño de ese campo donde va a iniciar su trabajo; a la vez, desenmascaramos con Martín al personaje de Emma, oprimido y verdugo, y descubrimos el sinsentido de su mensaje frente a la represión recibida. Con su inacción en el desarrollo de los actos, el personaje de Martín se construye desde la resignación a las imposiciones de Franco. En palabras de Tarantuviez, Gambaro «condena la pasividad de la víctima que sufre, en gran medida, por su silenciosa complicidad con el opresor [...] quienes no actúan para evitar su propia destrucción» (2007: 120) y es esta reflexión la que la autora, para Méndez-Faith, «nos deja como saldo o advertencia final» (1985: 841).

En relación a la violencia en los campos de concentración, la misma no es representada como el recuerdo de los actos de tortura ni existe una reconstrucción de los hechos traumáticos, como acontece en el teatro de la memoria. Por el contrario, se erige una violencia palpable, física, sufrida en primera persona por Martín y Emma. En el caso de ella, se presentará rapada, con la mano marcada, llena de heridas por

\footnotetext{
${ }^{5}$ Si bien Gambaro utiliza en esta primera etapa una actitud crítica ante la pasividad de las víctimas, en un deseo por despertar a la sociedad del letargo contra la opresión, su producción diferirá con el transcurso de los acontecimientos históricos y, especialmente, tras el Proceso de Reorganización Nacional (1976-1983). Con el inicio democrático, Argentina luchará por las reivindicaciones en pos de la Justicia y la Verdad. En el ámbito teatral también se establece una línea temática que reclama la memoria de los hechos ocurridos en contra del olvido. Es lo que Jorge Dubatti denominará «teatro de los muertos» (Dubatti 2014). La obra de Gambaro iniciará, con la época de los ochenta, un nuevo período donde la víctima cobra un carácter rebelde en enfrentamiento contra el poder y se inicia la reflexión sobre la memoria social, con textos como Real envido, La malasangre, Del sol naciente o Antígona furiosa.
} 
el cuerpo y cicatrices que solo desea rascar. Como apunta Diana Taylor, «las primeras obras de Gambaro, al igual que los modelos que emplea, más que explicar la violencia, la representan» (1989: 13-14).

No encontramos los tópicos memorialísticos recurrentes en las temáticas actuales. El espectador al que se dirige Gambaro en 1968 es coetáneo a estos hechos, por lo que la autora los recrea con la ferocidad necesaria para alertar a la sociedad de su situación similar, atrapados en la violencia y la pasividad. Además, la crueldad en El campo se incrementa, no solo en la recreación del horror, sino en el juego establecido por la dramaturga. Los mensajes ambiguos y la falsedad que envuelve este campo para Martín (desde el aspecto de los personajes al texto, gestos, acción u objetos) generan «significados truncados, equívocos o bisémicos, los cuales crean el ambiente de crueldad» (Picón Garfield 1980: 97). Es de esta forma, desde la recreación cruel de la experiencia en los campos de concentración nazi, desde la agresión estética ante el espectador, como Griselda Gambaro «intenta provocar al público para que recuerde y cuestione la realidad sociopolítica argentina» (Graham-Jones 1997: 265).

\section{La inefabilidad y el legado de la memoria: J'attendrai de J. R. Fernández}

Acercarnos entonces a la obra del dramaturgo madrileño José Ramón Fernán$d e z^{6}$ es situarnos ante un contexto diferente al de Gambaro. Fernández nace en Madrid en 1962 y le avala una amplia trayectoria, donde, entre los numerosos galardones, destaca el Premio Nacional de Literatura Dramática (2011) por su obra La Colmena científica o El café Negrín. A esta se unen, entre sus textos, Para quemar la memoria, La trilogía de la Juventud (Las manos, Imagina y 24/7, escrita junto a Javier Yagüe y Yolanda Pallín), La tierra, Babilonia, La ventana de Chigrinsky o Nina, entre otras, así como su subrayada labor como dramaturgo ${ }^{7}$.

En su obra, José Ramón Fernández ahonda en la reflexión crítica de la sociedad, lo que le conduce a temáticas como «la marginalidad, soledad, inmigración, la importancia del pasado histórico para entender el presente, así como una constante preocupación por la juventud» (Serrano Baxauli 2009: 83). Perteneciente a la generación de los nietos de la Guerra Civil española, inició su adolescencia tras el fallecimiento de Francisco Franco y con el inicio de la democracia. Si bien esta generación no conoció la represión de los años más cruentos del franquismo, su historia se ve marcada, desde la infancia, por el testimonio, el recuerdo, el trauma y la realidad social de la posguerra.

\footnotetext{
${ }^{6}$ Ante la imposibilidad de profundizar en el autor y su obra, remitimos a la tesis doctoral realizada por Rosa Serrano Baixauli (2015).

7 Dentro de la temática que aquí nos concierne, recordamos la dramaturgia que Fernández realizó de la obra colectiva Guardo la llave (1999), en el marco del Teatro del Astillero, donde jóvenes dramaturgos reflexionaban sobre el exilio republicano en 1939.
} 
Debemos recordar que el tardío inicio del proceso democrático en España generó una brecha con respecto a otros países europeos y los discursos que en ellos se asentaban en el ámbito de la memoria. Así, como señala Antonia del Amo (2014), será a partir de la década de los noventa -y extensible hasta nuestra contemporaneidad-, cuando se produzca un cambio de paradigma en el teatro de la memoria motivado por «el relevo de la llamada generación de los nietos, que, aliviada del miedo y del peso traumático de la experiencia, parece como depositaria de un legado soterrado y garante de su transmisión» (Amo 2014: 45) ${ }^{8}$. Además, «abunda en el nuevo teatro de la memoria el compromiso moral y político, así como el rechazo de la comprensión unívoca de la historia» (Amo 2014: 47). En relación a ello, como señala la historiadora Paloma Aguilar: «desde diversas posiciones [...] se mantiene que se ha silenciado la memoria histórica de los españoles, o que se les ha impuesto un olvido colectivo» (2008: 70).

La voz de José Ramón Fernández se une a la de una serie de dramaturgos contemporáneos donde ha tenido lugar una eclosión de lo memorialístico. En el caso particular de la temática de los campos de concentración, destacan textos como Himmelweg (en alemán 'camino al cielo') de Juan Mayorga; El convoy de los 927 y El triángulo azul de Laila Ripoll, el último escrito junto a Mariano Llorente, así como la producción de Max Aub, donde encontramos, entre su narrativa, textos dramáticos de temática concentracionaria como Morir por cerrar los ojos ${ }^{9}$. El interés destacado de la propuesta de José Ramón Fernández es situarnos ante una nueva perspectiva en este campo, la cual difiere de propuestas como la de Gambaro, así como por su carácter metateatral, a través del cual reflexiona sobre la propia recreación artística de la experiencia represiva de los campos. Además, se instaura dentro de un subtema común en la literatura española, el de los españoles republicanos exiliados que estuvieron recluidos en el campo de Mauthausen.

Ahondando en las particulares de $J^{\prime}$ attendrai, observamos que está construida en dos planos. En primer lugar, el plano de la historia lineal, donde Pepe, hombre nonagenario, y su nieto Vicent pernoctan, de camino a París, en el hotel de Claire. El anciano, republicano que luchó en la Guerra Civil española, formó parte de las filas francesas contra el ejército de Hitler hasta su captura y consiguiente reclusión en Mauthausen. A estos personajes les acompaña la imagen fantasmagórica de dos jóvenes,

\footnotetext{
${ }^{8}$ Como señala Álvarez Solís (2015) diversas voces críticas diferencian entre memoria histórica, historia del presente, estudios del trauma o lo denominado como «posmemoria». Con este último término, aplicable a la producción de Fernández, señala el investigador que «la posmemoria no consiste únicamente en el acto de recordar lo que no se ha vivido o la recepción autobiográfica de narrativas y obras artísticas producidas por una segunda generación; por el contrario, la posmemoria es un paradigma crítico que desvela los traumas no tematizados por una sociedad» (Álvarez Solís 2015: 42-43). También Floeck y García señalan que existen tres etapas en el teatro de la memoria en España: el «consenso e identificación (1975-1982)», «Crítica y reconciliación (1987-1990)» y, por último, «Contra-memorias, post-memoria y meta-memoria (1993-hoy)», donde se encuadraría la propuesta de Fernández.

9 Significativamente, José Ramón Fernández ha participado en un proyecto del Centro Dramático Nacional, encargándose de la versión escénica de las seis novelas que componen El laberinto mágico de Max Aub. Se estrenó el 7 de junio de 2016 en el Teatro Valle-Inclán del CDN con dirección de Ernesto Caballero.
} 
Claude y Patricia, a su vez abuela de Claire. Con el transcurso de la historia descubriremos que Pepe y Claude fueron compañeros en Mauthausen. Cuando el último intentó escapar y fue capturado, rogó a Pepe un cometido que nunca se cumplió: viajar a Francia y buscar a su novia, Patricia - exiliada republicana- para consolarla. El remordimiento por el favor no cumplido y la culpa y la vergüenza por haber sobrevivido al horror angustian a Pepe. Es ahora, ya anciano, cuando purga su desasosiego vital al contarle a la nieta de Claude, Claire, toda la verdad, consiguiendo homenajear a los muertos, reconstruir el pasado traumático y su propia historia.

Dentro de este plano, que denominaremos como A, encontramos a su vez tres subplanos: el ya narrado de Pepe, anciano, camino de París con su nieto; el de los fantasmas jóvenes de Claude y Patricia vagando por la estancia, atrapados en su historia de amor inconclusa, suspendida por la guerra; y, por último, las escenas en flash-back de Pepe y Claude en Mauthausen.

La obra de Fernández se distancia de la propuesta de Gambaro y construye mecanismos que caracterizan al teatro de la memoria en el ámbito español. Así, en J'attendrai percibimos, según la caracterización de Floeck y García Martínez: «una tendencia a la despolitización [...] a la subjetivización de la perspectiva, a la fragmentación y estructura abierta de la acción dramática, a la complejidad de las estructuras espacio-temporales»; además, señalan que, como observaremos en esta propuesta, se establece una «profunda reflexión metaficcional de las posibilidades y el proceso de reconstrucción de la realidad pasada» (Floeck 2011: 103-104).

En la narración de esta historia Pepe también intenta reconstruir su propio pasado e interroga, por vez primera, a su nieto sobre lo que conoce de la Segunda Guerra Mundial y de su pasado. El espectador comparte la mirada de Vicent, la de la generación de los nietos (y ya bisnietos), portadores de una nueva perspectiva y fuerzas renovadas para el encuentro con el pasado y la memoria. De esta forma, la obra de Fernández se inscribe, según la propuesta de Elizabeth Jelin, en una nueva línea de pensamiento donde «el énfasis está puesto en la preocupación por el legado y por la transmisión a las nuevas generaciones, lo que podríamos llamar la dimensión «pedagógica» de la memoria» (Jelin 2014: 226). Por ello, Pepe reconoce en el texto: «Era nuestra obligación. Hablar para que no se olvidaran de los muertos. Pero yo no he podido. No puedo. No puedo. Voy a abrir la boca y pienso «ipara qué?». Son cosas que parecen mentira. Son cosas que la gente no quiere oír» (Fernández 2014: 31).

Así, otra de las reflexiones primordiales del texto se basa en la transmisión de la memoria, en la reconstrucción del recuerdo para un nuevo receptor, para el público actual. En torno a este punto es donde se enlaza uno de los aspectos más interesantes de esta obra, lo que correspondería al plano B de la acción: el stasimo. Stasimo es un momento de la tragedia griega clásica en el cual se intercala en la acción un coro que comenta y analiza la situación que se está viviendo. En este caso, el coro lo compone un único personaje polifónico, el Yo, cuya aparición se entremezcla paulatinamente con la trama ya presentada. Ambos planos nos remiten al discurso de lo inefable, a la difícil transmisión y rememoración de la tragedia vivida en los campos de concentración. Como afirmó Irene Sadowska Guillon, en referencia al estreno en Francia de J'attendrai: «¿Cómo decir, expresar lo indecible, lo humano 
e inhumano del horror de la guerra? En J'attendrai saca el tono poético y la compañía un lenguaje escénico pluridisciplinar para resentirnos, entender la substancia indecible» (Sadowska 2016) ${ }^{10}$.

Además, el Stasimo se convierte en una parte de sumo interés para la comprensión del proceso creativo, para situar al dramaturgo dentro de las corrientes del teatro de la memoria y de esta temática, para conocer sus lecturas realizadas (Max Aub, Primo Levi, Antelme, Jorge Semprún...), las investigaciones históricas (Alfonso Maeso, Mariano Constante, Prisciliano García...), los dramaturgos que han trabajado con otras propuestas sobre el horror (Angélica Lidell, Tadeusz Kantor, José Luis Alonso de Santos, Laila Ripoll...); a su vez, el Yo remite a la propia experiencia personal, en un juego que fusiona al personaje coral y la imagen del dramaturgo, rememorando la historia de su tío Miguel Barberán, prisionero en Mauthausen.

A través de este Yo se realiza también un manifiesto a la escritura de su obra y a la literatura de la memoria cuando afirma: "Yo.- Una historia que no interesa a nadie, que no es lo que la gente quiere oír. Pero sabes que si hay algo que vale la pena que escribas, es esta historia» (Fernández 2014: 43). Fernández defiende desde la escena, como Beatriz Sarlo reflexionaría en Tiempo pasado, la imposibilidad de huir del recuerdo: «Proponerse no recordar es como proponerse no percibir un olor, porque el recuerdo, como el olor, asalta, incluso cuando no es convocado. Llegado de no se sabe dónde, el recuerdo no permite que se lo desplace» (Sarlo 2005: 9-10).

Por último, en referencia al título, J'attendrai (en francés 'te esperaré') recuerda a un tema de Dino Oliveri de 1937 con letra de Louise Poterar y N. Rastelli, sumamente popularizado en 1938 por Rina Ketty entre los enamorados separados por la batalla en la Segunda Guerra Mundial. Sin embargo, esta bella referencia se torna trágica en la obra al recuperarla Fernández de una de las historias narradas en el documental Mauthausen, el deber de recordar: cómo a Hans Bonarewitz, capturado tras intentar escapar, lo transportaron en una carretilla mientras sonaba de fondo esta canción. Como narra el Yo: «Te impresionó la crueldad de hacer oír a todos esa canción de amor y de esperanza para decirles «eso no pasará jamás». [...] Desde entonces, tus amigos conocen el título de esta obra que no sabías escribir» (Fernández 2014: 38). Sin embargo, es a su vez un título cargado de belleza, que enlaza con la historia de amor del texto y con la recreación del autor. Un dramaturgo consciente de que aún duermen muchas historias acalladas por la vergüenza, por el miedo, por la culpa y que esperan ser rescatadas.

\section{Conclusiones}

En definitiva, nos hemos adentrado en dos textos de sumo interés tanto por la originalidad de su construcción como por representar diferentes posibilidades en el tratamiento sobre la realidad traumática de los campos de concentración según el

10 La obra fue estrenada en Francia en enero de 2016 en el Théâtre à 1'Horizont en La Rochelle, con dirección de Claudie Landy y traducción de André Delmas. 
transcurso del tiempo. Griselda Gambaro, con su propuesta, buscaba desde la representación explícita de la violencia y la focalización en la pasividad de la víctima, incitar al espectador para que estableciera un correlato con su propia historia. Por su parte, la distancia que separa a José Ramón Fernández de la Segunda Guerra Mundial nos sitúa en un nuevo plano, dirigiéndose a las nuevas generaciones para reconstruir la Historia e invitar al espectador a luchar en pos de la transmisión de la memoria, así como reflexiona sobre la propia actividad creadora en esta temática tan comprometida, mientras nos presenta a los fantasmas que aún caminan entre nosotros y a quienes debemos recordar para no olvidar - ni repetir- los crímenes cometidos.

\section{Referencias bibliográficas}

Aguilar Fernández, Paloma (2008): Políticas de la memoria y memorias de la política. Madrid: Alianza Editorial.

Álvarez Solís, Ángel Octavio (2015): «La posmemoria en México. De la experiencia postraumática a la experiencia postaurática». En Memorias iberoamericanas: historia, politica y derecho, David Soto Carrasco, José Nefatlí Nicolás García y Francisco Manuel García Costa (eds.), pp. 41-66. Pamplona (Navarra): Thomson Reuters Aranzadi.

AMo SÁNCHEZ, Antonia (2014): «Dramaturgias de lo imprescriptible: un teatro para la recuperación de la memoria histórica en España (1990-2010)». Anales de literatura española contemporánea 39 (2): 39-67.

AzConA, José Manuel (2010): Violencia política y terrorismo de Estado en Argentina. Del totalitarismo de José Uriburu (1930) a la dictadura militar (1976-1983). Una visión bilateral. Madrid: Biblioteca Nueva.

DuBATTI, Jorge (2007): Filosofía del teatro I. Convivio, experiencia, subjetividad. Buenos Aires: Atuel.

- (2014): Filosofía del teatro III. El teatro de los muertos. Buenos Aires: Atuel.

FERNÁNDEZ, José Ramón (2014): J'attendrai. Texto manuscrito.

FLOECK, Wilfried y GARCÍA MARTÍNEZ, Ana (2011): «Memoria y olvido entre bastidores: Guerra Civil y franquismo en el teatro español después de 1975». En Escribir después de la dictadura. La producción literaria y cultural en la posdictaduras de Europa e Hispanoamérica, Janett Reinstädler (ed.), pp. 97-119. Madrid / Frankfurt: Iberoamericana Vervuert.

GAmbaro, Griselda (1990): Teatro 4. Las paredes. El desatino. Los siameses. El campo. Nada que ver. Buenos Aires: Ediciones de la Flor.

GRAHAM-JONES, Jean (1996): «De la euforia al desencanto y al vacío: la crisis nacional en el teatro argentino de los 80 y 90». En Memoria colectiva y políticas de olvido. Argentina y Uruguay, 1970-1990, Adriana J. Bergero y Fernando Reati (comp.), pp. 253-277. Rosario: Beatriz Viterbo Editora.

MÉNDEZ-FAITH, Teresa (1985): «Sobre el uso y el abuso de poder en la producción dramática de Griselda Gambaro». Revista iberoamericana. LI, No 132-133: 831-841.

JELIN, Elizabeth (2014): «Memoria y democracia. Una relación incierta». Revista mexicana de ciencias políticas y sociales LIX, 221: 225-242.

PelletTIERI, Osvaldo (2003): Historia del teatro argentino en Buenos Aires. Volumen IV. La segunda modernidad (1969-1976). Buenos Aires: Galerna. 
SAdowsKa GuILlon, Irene (2016): «¿Cómo contar lo indecible?». En Artezblai. El periódico de las Artes Escénicas. 12 de febrero de 2016. En: http://www.artezblai.com/artezblai/jattendraijose-ramon-fernandezclaudie-landy.html. [Consulta: 29/05/2016]

SARLo, Beatriz (2005): Tiempo pasado. Cultura de la memoria y giro subjetivo. Una discusión. Buenos Aires: Siglo XXI Editores.

SÁNCHEZ ZAPATERO, Javier (2010): Escribir el horror. Literatura y campos de concentración. Barcelona: Editorial Montesinos.

SERRANO BAIXAUl, Rosa (2009): «José Ramón Fernández: un teatro para y sobre personas». Stychomythia 9: 82-88.

- (2015): Una escritura comprometida con su tiempo. El teatro de José Ramón Fernández (1992-2012). Tesis Doctoral. Universidad de Valencia.

TARANTUVIEZ, Susana (2007): La escena del poder. El teatro de Griselda Gambaro. Buenos Aires: Corregidor.

TAYLOR, Diana (1989): «Paradigmas de crisis: la obra dramática de Griselda Gambaro». En En busca de una imagen. Ensayos críticos sobre Griselda Gambaro y José Triana, Diana Taylor (ed.), pp. 11-23. Canadá: Girol Books. 